\title{
Multiple endocrine neoplasia 2A (MEN 2A) syndrome
}

\author{
Breza J Jr, Breza J Sr \\ Department of Urology with the Center for Kidney Transplantation, University Hospital Bratislava, Slovakia. \\ janbreza@gmail.com
}

\begin{abstract}
INTRODUCTION: In the MEN 2A syndrome, which is the most common of the three types of MEN, three endocrine systems are affected simultaneously or subsequently by the development of tumours manifested by medullary thyroid gland carcinoma, pheochromocytoma (often bilateral) and hyperparathyroidism.

MATERIAL AND METHODS: 27 patients from 3 families affected by MEN 2A syndrome were examined clinically (by detecting the effects of catecholamine overproduction), biochemically (screening for metanephrine and normetanephrine in the serum), visualization (CT, MRI, MIBG, PET CT) and some of them also genetically (DNA fragment analysis obtained by PCR amplification).

RESULTS: Familial incidence of pheochromocytoma was confirmed in 10 patients (4 males, 5 females and one girl) aged 6 to 54 years (average 22.8 years) . In 5 patients, the pheochromocytoma occurred on both sides, in one patient, with genetically proved MEN 2A syndrome, only one adrenal gland was affected by pheochromocytoma. In 10 patients, mutations were detected in the exon 10, 11 and 16 RET of the proto-oncogene in the centromeric region of the 10th chromosome. After proper preparation, 5 patients underwent bilateral adrenalectomy (unilateral adrenalectomy in one patient). Histological examination of the removed tumours in all cases excluded the malignant pheochromocytoma.

The first of the operated patients (54 yr) died after surgery for cardiovascular failure. Others have lived 5 to 15 years after bilateral adrenalectomy without signs of local recurrence of the disease, and have no clinical signs of over-production of catecholamines.

CONCLUSION: Bilateral pheochromocytoma and thyroid carcinoma are indications for detailed clinical and genetic examination of all family members. Bilateral adrenalectomy with lifetime supplementation of adrenal hormones is indicated in symptomatic patients and/or patients asymptomatic with tumours larger than $3 \mathrm{~cm}$ in diameter (Tab. 1, Fig. 11, Schema 1, Ref. 31). Text in PDF www.elis.sk.

KEY WORDS: pheochromocytoma, paraganglioma, RET proto-oncogene.
\end{abstract}

\section{Introduction}

Pheochromocytoma is a tumor of the chromaffin tissue derived embryologically from the neural crest and arising from adrenal medulla, carotic and aortic chemoreceptors and cervical, thoracic and abdominal sympathetic ganglia. The tumor has been termed „the $10 \%$ tumor" as approximatelly $10 \%$ of pheochromocytomas are extraadrenal, bilateral, multiple, familial and malignant. Tumors arising from the extraadrenal chromaffin tissue are called paragangliomas (Figs 1 and 2). Most pheochromocytomas occur sporadically, unilaterally and in the form of a solitary tumor. About $10 \%$ of pheochromocytomas have the nature of a familial disease. Most of these tumors occur as part of multiple endocrine neoplasia (MEN 2 syndrome, von Hippel-Lindau syndrome or type 1 neurofibromatosis). Though the syndromes are unusual lesions (incidence much less than 1 out of 100000 population per year), the urologists must neverthless be familiar with their diagnosis and management.

Department of Urology with the Center for Kidney Transplantation, University Hospital Bratislava, Bratislava, Slovakia

Address for correspondence: J. Breza, MD, PhD, Department of Urology with the Center for Kidney Transplantation, University Hospital Bratislava, Limbova 5, SK-833 05 Bratislava, Slovakia.

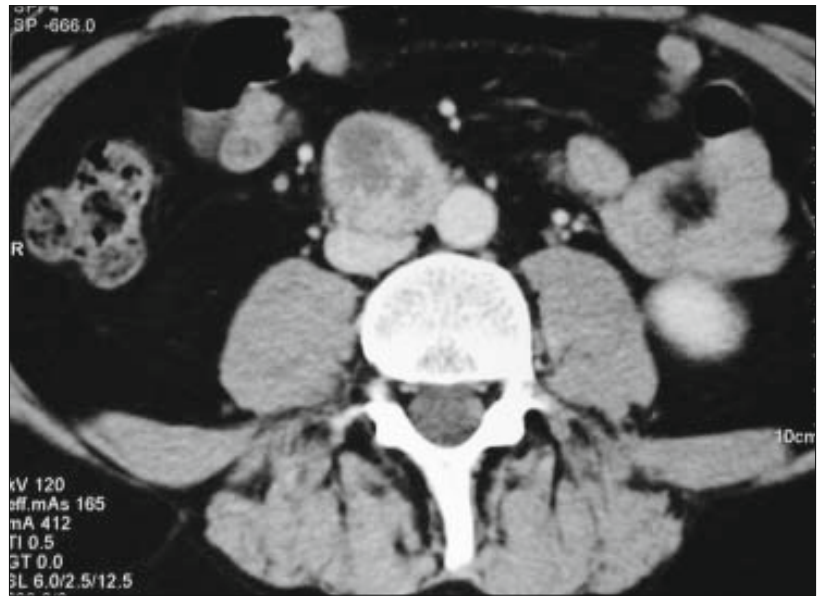

Fig. 1. Precavally localised paraganglioma, histologically benign, no genetic changes typical for MEN $2 \mathrm{~A}$ syndrome.

The Multiple Endocrinne Neoplasia syndrome (MEN) is an autosomal dominant hereditary disorder caused by activated germline mutations in the RET proto-oncogene on chromosome 10, which results in development of 2 or more tumors of the endocrine glands in the same patient (Hadoux et al, 2016). Based on the clinical 
Tab. 1. Tumors of the adrenal gland.

\begin{tabular}{lcccc}
\hline Diagnosis & Males & Females & Total & $\%$ \\
\hline Cortical adenoma & 18 & 79 & 97 & 44.9 \\
Cortical carcinoma & 8 & 15 & 23 & 10.6 \\
Cortical hyperplasia & 4 & 10 & 14 & 6.4 \\
Pheochromocytoma & $\mathbf{1 9}$ & $\mathbf{3 9}$ & $\mathbf{5 8}$ & $\mathbf{2 5 . 9}$ \\
Myeloma & - & 7 & 7 & 3.2 \\
Ganglioneuroma & 3 & 2 & 5 & 2.3 \\
Pseudocyst & - & 5 & 5 & 2.3 \\
Adrenal metastasis & 6 & 1 & 7 & 3.2 \\
\hline Total & 58 & 158 & 216 & \\
\hline
\end{tabular}

manifestation, 3 types of MEN syndrome can be distinguished. MEN 2A is the most common form and includes medullary thyroid carcinoma, pheochromocytoma and parathyroid adenoma or hyperplasia. Pheochromocytomas occur in 10 to $50 \%$ of patients with MEN 2A syndrome, up to $70 \%$ of which are bilateral pheochromocytomas. Pheochromocytoma penetrance and age at diagnosis are highly correlated with MTC aggressivenes based on RET mutation status, with higher penetrance and younger age at diagnosis associated with more aggressive MTC . Penetrance steadily increases with age (Mucha et al, 2017, Lu et al, 2017). About $20-30 \%$ of all cases of multiple endocrine neoplasia type $2 \mathrm{~A}$ is accompanied by primary hyperprathyroidism (Kim et al, 2016). Early diagnosis, both clinical and genetic, allows achieving good therapeutic results. Genetic analysis of RET proto-oncogene allows identifying the pathological gene carrier prior to its clinical manifestations, further improving the possibility of an effective treatment and survival of patients with this disease (Mathiesen et al, 2017). . Pheochromocytoma is considered a very severe tumor that, if not diagnosed and treated early, leads to serious complications and mortality.

The aim of the work is to describe the own experience with the diagnostics and treatment of pheochomocytomas that are the part of MEN 2A syndrome.

\section{Material and methods}

In the last two decades we have performed 216 adrenalectomies for various types of adrenal tumors (Tab. 1). 58 out of them have been pheochromocytomas and included both symptomatic and asymptomatic forms with benign and malignant histological patterns, unilateral, bilateral, recurrent, ranging from 20 to 740 grams in weight. They occured more frequently in females (39 patients aged 6 to 79 years). 19 men were 18 to 66 years old. Pheochromocytomas accounted for $25.9 \%$ of 216 patients treated in this period for other surgical adrenal diseases.

6 out of 58 patients operated for pheochromocytoma were members of three families affected by MEN 2A syndrome. Patients with familial incidence of pheochromocytoma were younger than those with sporadically occurring pheochromocytomas (6 to 54 years, mean 31,1 yr versus 18 to 79 years, mean 54.4). Three of six patients suffered from hypertension, in other three patients pheochromocytomas were detected by active screening after surgery for thyroid medullary carcinoma. In 5 patients

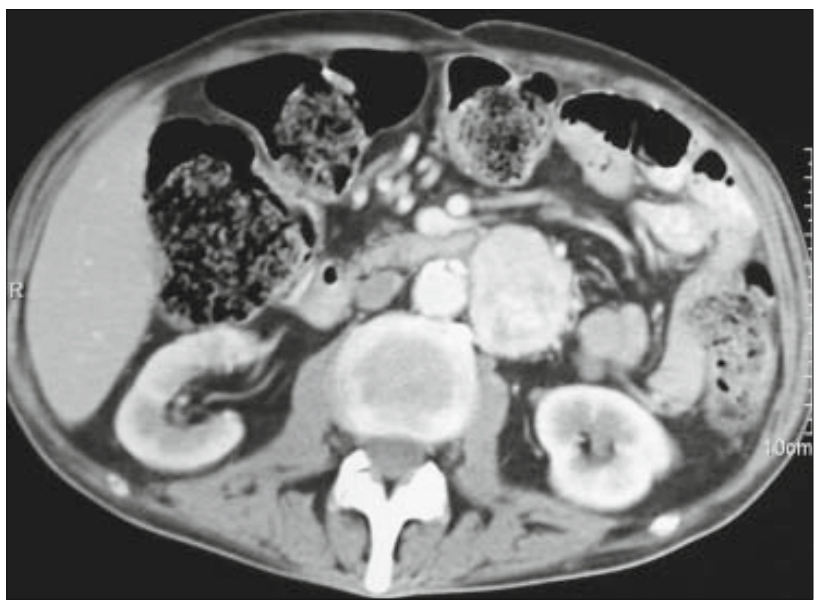

Fig. 2. Histologically malignant paraganglioma localised in paraaortal region.

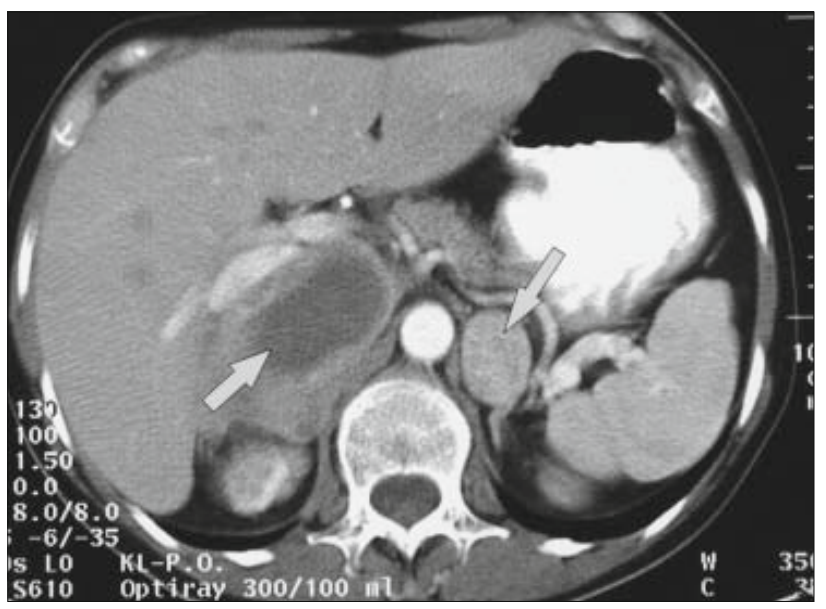

Fig. 3. Bilateral pheochromocytoma (arrows) in a patient with MEN 2 A syndrome.

pheochromocytomas occured on both sides, in one patient, with genetically proved MEN 2A syndrome, the adrenal tumor occured unilaterally.

Diagnostics of pheochromocytoma relied on standard biochemical and imaging examinations. For clinical screening of pheochromocytomas and also for differential diagnosis of different forms of hypertension, the computer guided discriminative analysis of subjective symptoms and objective signs was utilized. When a patient was suspected to suffer from a pheochromocytoma, investigation was directed towards confirmation of excessive catecholamines secretion (adrenalin, noradrenalin, metanephrin and normetanephrin in serum and urine, in addition vanylmandelic acid in urine) and localization the source of catecholamines production and the site of the lesion.

Once the diagnosis of pheochromocytoma was confirmed biochemically, the exact position and the size of the lesion was identified before surgical therapy was planned. CT scanning was accurate in identifying the adrenal lesions (Figs 3 and 4). 


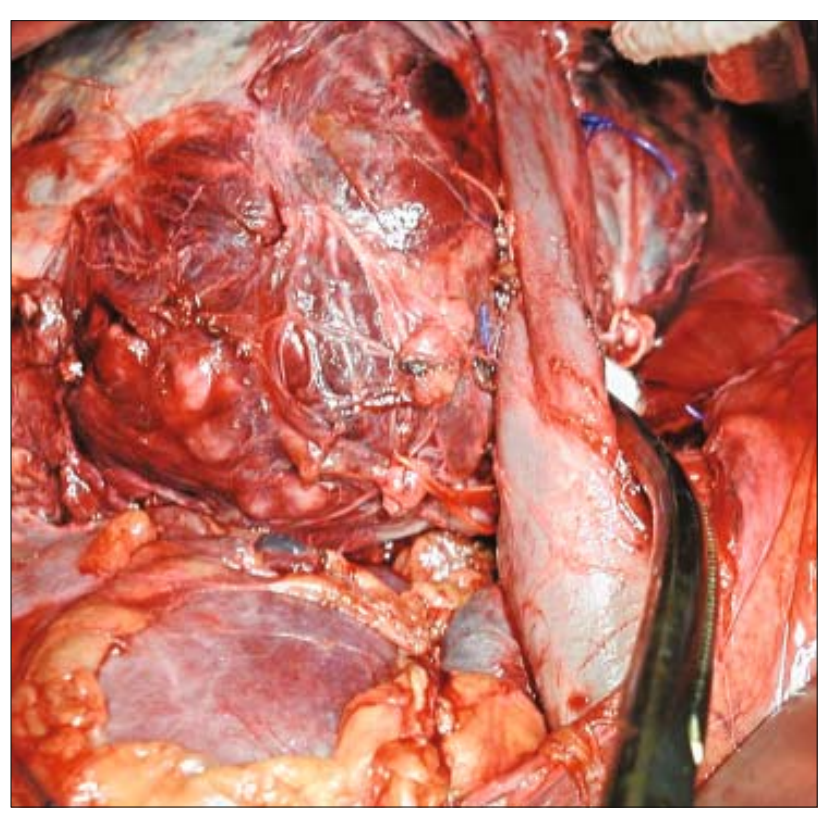

Fig. 4. Retrocaval (right side) pheochromocytoma in patient from Figure 3.

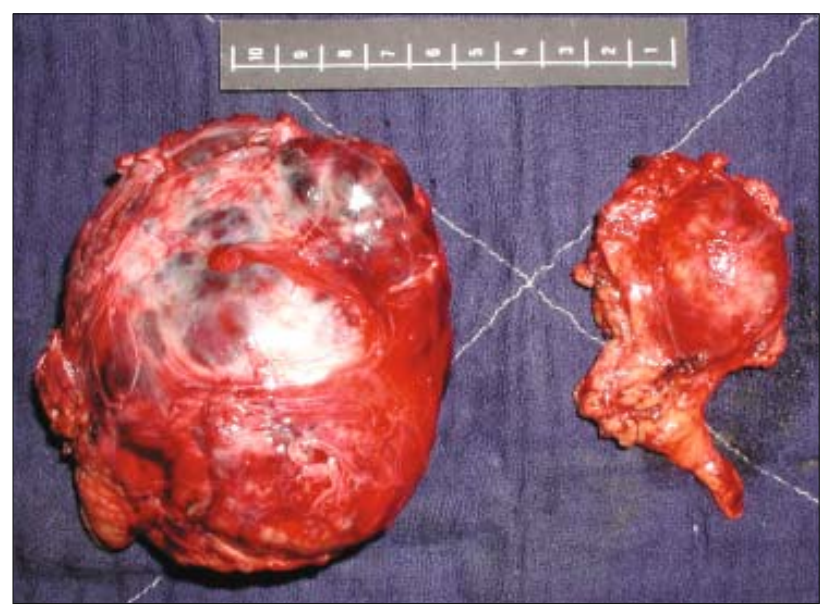

Fig. 5. Removed pheochromocytomas of bilateral adrenal glands (from patient on Figs 3 and 4).

\section{Results}

In 28 out of 216 patients, the adrenal tumor have been diagnosed incidentally (including 5 pheochromocytomas).

After preoperative medication, 5 patients with MEN 2A syndrome underwent bilateral adrenalectomy in one session through transverse laparotomy as a surgical approach (Fig. 5). In one patient only left-side adrenalectomy was performed via extraperitoneal lumbotomy. Pheochromocytomas in these patients were smaller (20 to 120 grams) than in patients with sporadically occuring pheochromocytomas. By histological examination, benign morphological features were demonstrated in all removed pheochromocytomas. Both the peroperative and postoperative periods were uncomplicated in five patients. One patient (54 years old) died of cardiovascular failure, the other 5 survived in good condition 3 to 15 years after surgery.

The hereditary pheochromocytoma is often associated, besides MEN 2A and MEN 2B syndrome, also with von Recklinghausen fibromatosis and von Hippel Lindau syndrome. Genetic analysis of sporadic pheochromocytomas revealed a $20 \%$ presence of RET mutations, while in von Hippel Lindau syndrome this mutation was detected in $20 \%$ patients and in $45 \%$ of cases the loss of heterozygosity was proven. Interestingly, no genetic abnormalities were found in the sporadic extraadrenal type of pheochromocytoma (the so-called paraganglioma).

Genetic testing in the diagnosis of MEN 2A in our patients was based on analysis of DNA fragments obtained by PCR amplification. Mutations in exon 10, 11 or 16 of the RET proto-oncogene in the centromeric region of chromosome 10 was observed in 10 out of 27 members $(38.5 \%)$ of the three families (Schema 1).

6 patients underwent surgical therapy. Other 4 members of these families with a proved genetic mutation have undergone complete clinical and imaging examination. Neither affection of the thyroid gland nor medullary carcinoma was detected. These patients are regularly monitored, informed on their health status and the risks that may affect them, so they go to regular checks once a year.

\section{Discussion}

Multiple endocrine neoplasia syndrome is a very rare condition. Its occurence is reported to be 1-3 cases per million of inhabitants per year. This is a simultaneous or subsequent affection of three endocrine systems.

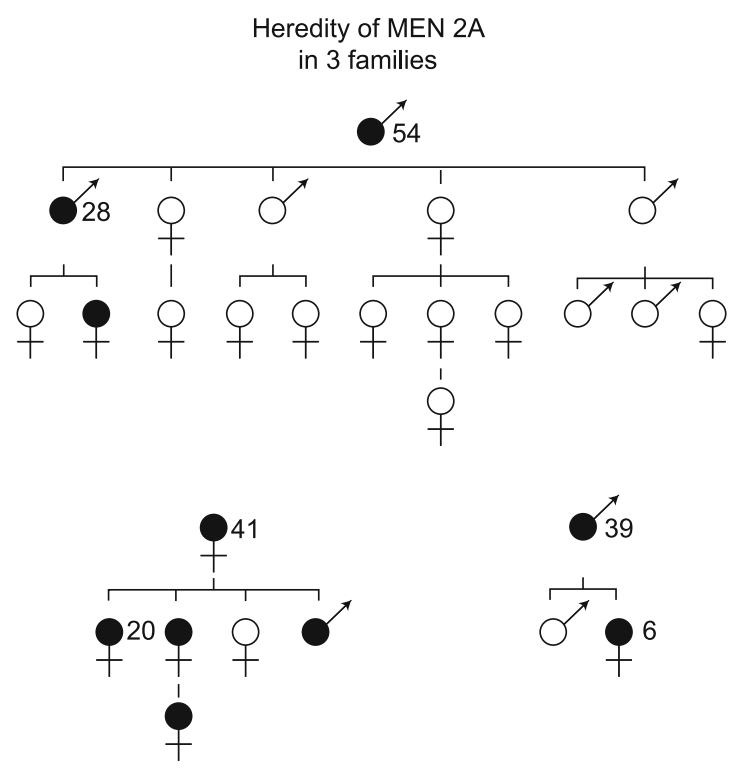

(age is indicated only in patients treated by bilateral adrenalectomy)

Schema 1. Hereditary of MEN 2A in three families. 


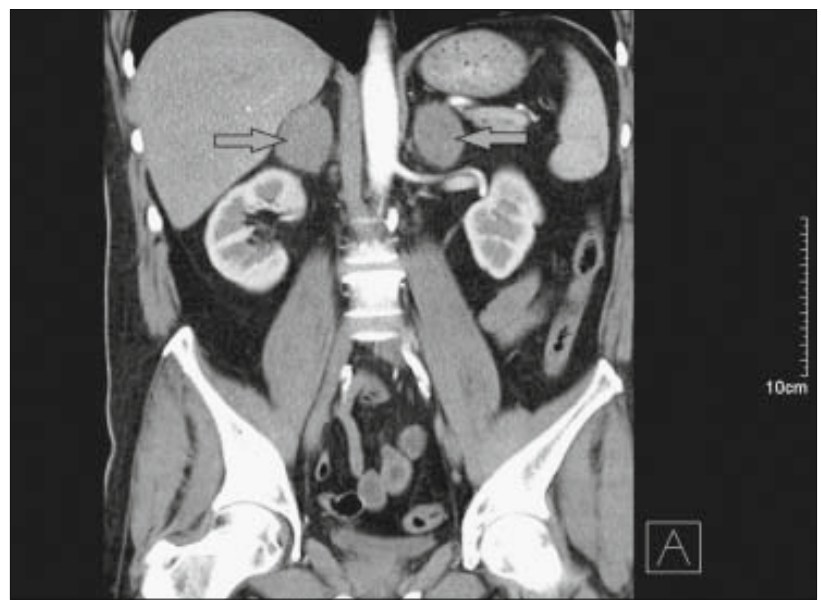

Fig. 6. Bilateral pheochromocytoma.

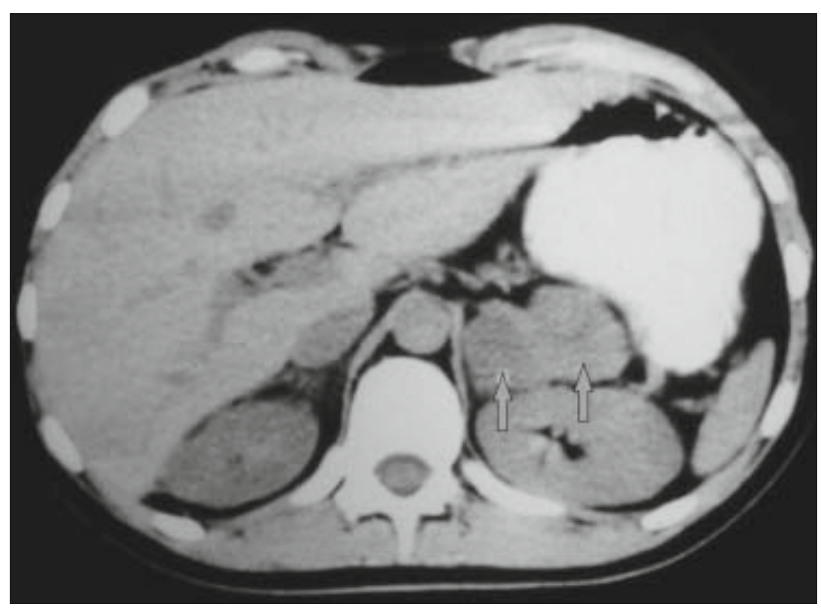

Fig. 7. Concurrent occurrence of pheochromocytoma and paraganglioma on the left side.

Both MEN 2A and MEN 2B syndromes are inherited in an autosomal dominant manner with incomplete penetrance and variable expressivity. Any child of an affected parent has a 50 : 50 chance of inheriting the gene. Transmission is equal through males and females. However, in approximately $1 / 3$ od individuals who inherit the MEN 2A gene, the disease does not develop to lead them to seek medical help.

Three varieties of MEN 2 syndrome can be distinguished on clinical basis. MEN 2A is the commonest form of MEN 2, characterized by the occurence of bilateral pheohromocytoma, medullary carcinoma of the thyroid and parathyroid adenoma or hyperplasia. All patients with MEN 2A syndrome suffer from medullary carcinoma of the thyroid. MTC is often the first manifestation of this subtype and the predominant cause of death in patients with MEN 2A. Pheochromocytomas occur only in 10 to $50 \%$ of MEN $2 \mathrm{~A}$ patients, with $70 \%$ of these being bilateral or recurrent pheochromocytomas (Fig. 6). Parathyroid disease occurs in about $20 \%$ of patients with MEN 2A syndrome.

MEN 2B syndrome accounts for about $5 \%$ of MEN cases and includes medullary carcinoma of the thyroid, pheochromo- cytoma and musculoskeletal abnormalities (Marfanoid habitus, pectus excavatum, hypotonia, proximal muscle weakness), characteristic facial appearance with thickened eyelids and neuromas of the lips and tongue.

The third and and the rarest type of MEN 2 is a familial medullary carcinoma of the thyroid - only disease, inherited as an autosomal dominant trait, with no associated adrenal or parathyroid involvement. Additionally, a small number of patients exhibit skin lichen amyloidosis or Hirschsprung's disease (Ying a Feng, 2016).

Because of clinical symptoms and laboratory signs, pheochromocytoma is usually detected earlier than MCT and may be the first sign of the disease in patients with MEN 2A.

6 out of 58 operated patients ( 4 males and 2 females) have been the members of three families affected by MEN 2A syndrome. Patients with pheochromocytomas as a part of MEN 2A were slightly younger comparing to the rest of the pheo group (Tab. 1). 3 out of 6 patients have been symptomatic (paroxysmal or sustained hypertension, headaches, pallor, sweating, palpitations, myocardial infarction, hypertensive encephalopathy). In 2 patients the pheochromocytomas have been detected by active screening after they have undergone thyroidectomy for MCT. The youngest patient (6 years old girl) was asymptomatic. In 5 patients the pheochromocytoma occured bilaterally, in one patient pheochromocytoma and paraganglioma occured simultaneously on one side (Fig. 7).

For clinical screening of pheochromocytoma and also for differential diagnosis of different forms of hypertension, the computer guided discriminative analysis of subjective symptomas and objective signs was utilized by the closely co-operating medical departmens. The most common symptoms, except severe hypertension, include headache, palpitations and sweating.

We use catecholamines in serum and urine to diagnose pheochromocytoma. The most precise results are gained by determining metanephrine and normetanephrine in serum (sensitivity up to 99 $\%$ ). Determination of vanillylmandelic acid and free metanephrin in urine is not considered to be sufficiently sensitive.

Besides catecholamines, the pheochromocytoma produces a whole range of active peptides - somatostatin, adrenocorticotropin, endorphin, lipotrophin, VIP, interleukin 6, calcitonin, serotonin, gastrin, neurotensin and others (Pacak et al, 2001). Secretion of these substances can lead to an atypical clinical symptomatology.

When a patient is suspicious of have a pheo, investigation is directed towards confirmation of excessive catecholamine secretion and localization of the side and size of the lesion by vizualization studies. After confirmation of an increased hormonal activity we search for a hyperpoductive tumor in the adrenal medulla or rarely in sympathetic ganglia. The USG examination is only indicative also in the case of a positive finding asi t has a low sensitivity and specificity. The gold standard is a CT scan. MRI has a higher specificity than CT scan. A valuable method is meta-iodobenzylguanidin gammagraphy - MIBG (Fig. 8) which confirms whether a randomized or targeted tumor produces catecholamines. It is mainly used for suspicion of disease dissemination or unusual tumor localization. PET CT (6-18F-Dopa) has a $94 \%$ sensitivity and $100 \%$ specificity. 


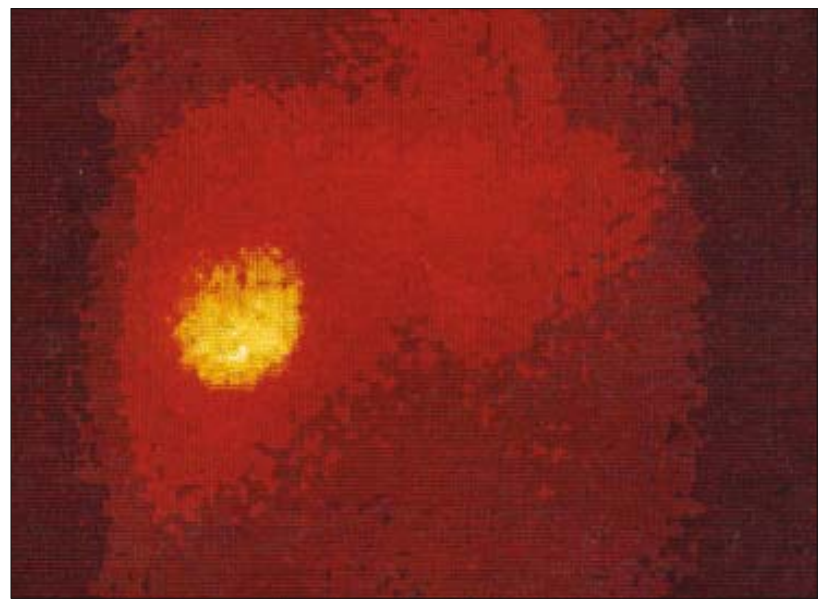

Fig. 8. Right side pheochromocytoma demonstrated by metaiodobenzylguanidine (mIBG) scintigraphy.

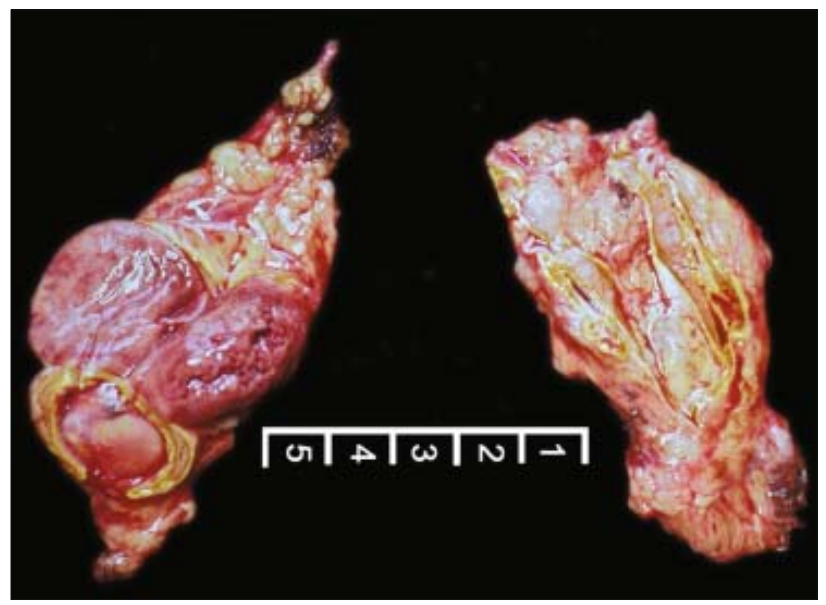

Fig. 9. Removed both adrenal glands affected by pheochromocytoma.

The treatment of pheochromocytoma is surgical (Fig. 9). We used an open surgery, transabdominal approach. However, laparoscopic adrenalectomy is currently the method of choice. Prior to surgery, however, specialized pre-operative preparation is essential which mainly involves adjusting the blood pressure and supplementing the volume of circulating blood (Majek et al, 1996). During surgery, we try to minimize manipulation of the tumor and primarily ligate adrenal vessels. Pheochromocytoma is usually encapsulated, brown - red, with honeycomb struture and strongly vascularized (Fig. 10). Patients with MEN2 had smaller tumors what may be related to the fact that a higher proportion of MEN2 patients received regular monitoring because of a known mutation (Butz et al, 2017).

\section{Conclusions}

All principles valid for the diagnosis and treatment of adrenal tumors can also be applied to patients with MEN 2A. A bilateral pheochromocytoma is an indication for detailed clinical and ge-

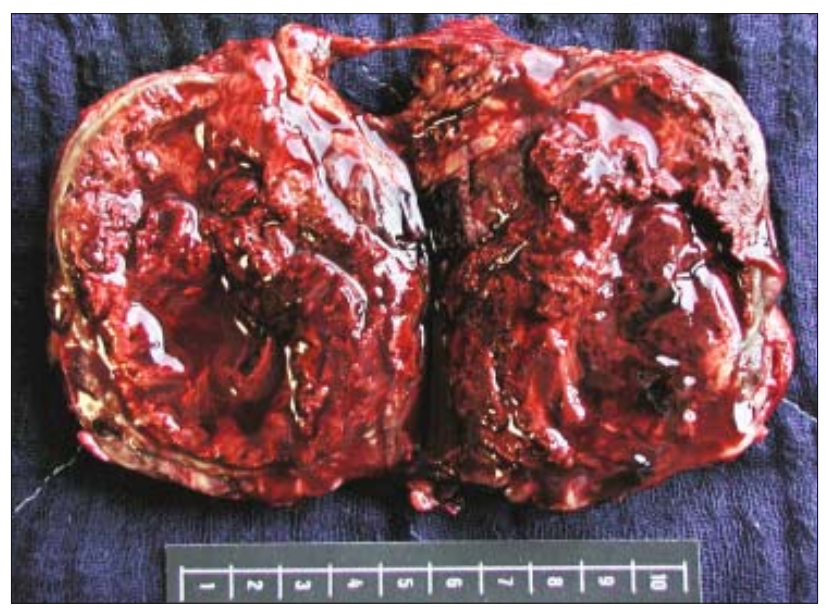

Fig. 10. Transverse section of pheochromocytoma. Brown-red colour, honeycomb strucure as a consequence of parenchymal necrosis.

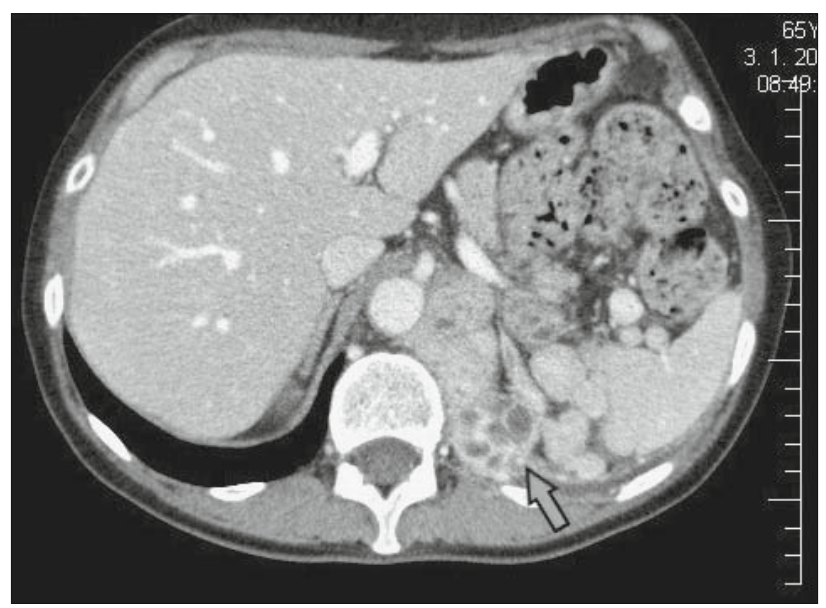

Fig. 11. Local recurrence of malignant pheochromocytoma (arrow) 15 years after histologically benign pheochromocytoma was removed.

netic examination of all family members. Genetic examination will help to identify those patients who require monitoring rather than immediate surgical treatment. The finding of medullary thyroid carcinoma is also a reminder for a thorough examination of the affected patients.

Bilateral adrenalectomy is indicated in symptomatic patients and in asymptomatic patients with tumors larger than $3 \mathrm{~cm}$ in diameter. In patients with bilateral adrenal tumor, pre-operative examination and consistent postoperative monitoring is vital. $\mathrm{Pa}-$ tients after bilateral adrenalectomy require lifelong supplementation of adrenal hormones. The biological properties of pheochromocytomas, not only in patients with MEN 2A syndrome, cannot be determined by any morphological or histological method. The only absolute criterion for malignity of the pheochromocytomas is the presence of distant metastases, lymph nodes involvement or local recurrence of the tumor. As an example we have reported a local recurrence of malignant pheochromocytomas in three patients, 10, 15 and 30 years after adrenalectomy for histologically benign lesion (Fig. 11). 


\section{References}

1. Aghdam MN, Abbaszadegan MR, Tafazoli A, Aslzare M, Mosavi Z. Presence of the RET Cys634Tyr mutation and Gly691Ser functional polymorphism in Iranian families with multiple endocrine neoplasia type 2A. Hormones 2016; 15 (1): 65-72.

2. Butz JJ et al. Perioperative outcomes of syndromic paraganglioma and pheochromocytoma resection in patients with von Hippel-Lindau disease, multiple endocrine neoplasia type 2 , or neurofibromatosis type 1 . Surgery 2017; 162 (6): 1259-1264.

3. Blazicek P, Langos J. Mnohopočetná endokrinná neoplázia. Bratislava, MAPA Slovakia Plus, s.r.o, 2012, 88 pp.

4. Balažovjech I, Makaiová I, Breza J, Májek M, Bujdák P. Diagnostika a liečba nádorov drene nadobličiek. Urológia 2000; 6: 11-13.

5. Boybeyi-Turer O, Vuralli D, Karnak I, Gonc N, Yalcin ES, Orhan D, Kandemir N, Tanyel FC. Surgical and clinical strategies in the management of thyroid medullary carcinoma in children with and without ret proto-oncogene mutations. Turk J Pediat 2016; 58: 436-441.

6. Breza J, Zvara V, Balazovjech I, Kreze A, Miklosi M. Adrenal Incidentalomas. Eur Urol 1998; 33: 203.

7. Breza J, Miklosi M, Bujdak P, Balazovjech I, Pauer M. Incidental pheochromocytomas. Eur Urol 1999; 35: 5.

8. Breza J, Miklosi M, Bujdak P, Balazovjech I, Podobova M, Majek M. The MEN 2A (Multiple Endocrinne Neoplasia) syndrome. Abstract Book. Vth Middleeuropean Countries of Internal Medicine. Bratislava, June 29-30, 2000, p. 47.

9. Breza J. Physiology and pathophysiology of adrenals. Preoperative preparation. Eur. School of Urology, course 16 „Adrenal Tumors“. Geneva, Switzerland, 2001; 8 (4): 1-10.

10. Breza J, Bujdak P, Bardos A, Hladik M. Tumors of sympathicoadrenal system. Urologischer Winterforum, Maria Alm, Austria, 25.31.1.2004, p. 82 .

11. Breza J, Zvara V, Balazovjech I, Kreze A. The need and possibilities to improve early diagnosis of adrenal tumors. EAU XIIth Congress, Paris, September 1-4, 1996.

12. Breza J, Vajó J. Diagnostika a liečba nádorov nadobličiek. 283-295. In: Eds. Breza J. et al. Princípy chirurgie IV. Bratislava: Slovak Academic Press, 2015, $1032 \mathrm{~s}$.

13. Goncalvesova E, Breza J, Hnilica P, Goncalves F, Motovska Z. Adrenal incidentalomas - Analysis of 25 cases detected by ultrasound. Cancer Detection and Prevention 1998; 22: 155.

14. Hadoux J, Féraud O, Griscelli F, Opolon P, Divers D, Gobbo E, Schlumberger M, Bennaceur-Griscelli A, Turhan A.G. Generation of an induced pluripotent stem cell line from a patient with hereditary multiple endocrine neoplasia 2A (MEN2A) syndrome with RET mutation. Stem Cell Res 2016; 17: 154-157.

15. Jarolím L, Breza J, Wunderlich H. Adrenal Tumors. Eur Urol 2003; 43 (Curric. Urol. 1. - X).

16. Ježová D. Sympatiko-adrenomedulárny systém. 403-411. In: Kreze A, Langer P, Klimeš I, Stárka L, Payer J, Michálek J. Všeobecná a klinická endokrinológia. Bratislava, Academic Electronic Press, 2004, 910 p.
17. Junker K, Gruschwitz T, Breza J, Wunderlich H, Schubert J. Improvements of histopathological classification of adreno-cortical tumors by genetic differentiation? Eur Urol Supp. 2005; 4: 4.

18. Kim BK, Lee J, Sun WY. Recurrent hyperparathyroidism due to proliferation of autotransplanted parathyroid tissue in a multiple endocrine neoplasia type 2A patient. Ann Surg Treat Res 2016; 91 (3): 145-148.

19. Langoš J, Blažíček P. Nádory sympatikoadrenálneho systému. S. 412-421. In: Kreze. A, Langer P, Klimeš I, Stárka L, Payer J, Michálek J. Všeobecná a klinická endokrinológia. Bratislava, Academic Electronic Press, 2004, 910 p.

20. Lu F, Chen X, Bai Y, Feng Y, Wu J. A large Chinese pedigree of multiple endocrine neoplasia type 2A with a novel C634Y/D707E germline mutation in RET exon 11. Oncol Let 2017; 14: 3552-3558.

21. Májek M, Koutun J, Zvara V, Breza J, Balažovjech I. Porovnanie klinického obrazu a hemodynamických parametrov v predoperačnej príprave feochromocytómu. Lek. Obzor 1996; 45: 212-215.

22. Mathiesen JS, Kroustrup JP, Vestergaard P, Stochholm K, Poulsen P.L, Rasmussen AK, Rasmussen LF, Gaustadnes M, Orntoft TF, van Overeem Hansen T, Nielsen FC, Brixen K, Godballe C, Frederiksen AL. Distribution of RET mutations in multiple endocrine neoplasia 2 in Denmark 1994-2014: A Nationwide study. Thyroid 2017; 27 (2): 215-219.

23. Majek M, Kula R, Zvara V, Breza J. Préparation avant opération pour phéochromocytome. Ann. Urol. 1996; 30: 20-24.

24. Mucha L, Leidig-Bruckner G, Frank-Raue K, Bruckner T, Kroiss M, Raue F. Phaechromocytoma in multiple endocrine neoplasia type 2: RET codon-specific penetrance and changes in management during the last four decades. Clin Endocrinol 2017; 87: 320-326.

25. Ohta S, Lai EW, Pang ALY, Brouwers FM, Chan WY, Eisenhofer G, deKrijgers R, Ksinantova L, Breza J, Balazovjech I, Kvetnansky R, Wesley RA, Pacak K. Downregulation of metastatic suppressor genes in malignant pheovhromocytomas. Int J Cancer 2005; 144: 139-143.

26. Pacak K, Ksinantova L, Breza J, Eisenhofer DG. Nejnovější informace o biochemické diagnostice a lokalizaci feochromocytomu. Bratisl Lek Listy 2001; 27 (4): 20-22.

27. Potunajová M, Altnerová V, Kettmann R, Feiková S, Hlubinová K, Balažovjech I, Breza J, Fodor G, Knotek J, Matoška J, Podobová M, Altaner C. Germline mutation of the RET proto-oncogene in members of Slovak families with multiple endocrine neoplasia. Neoplasma 2001; 48: 445-450.

28. Sipple JH.The association of pheochromocytoma with carcinoma of the thyroid gland. Am J Med 1961; 31: 163-166.

29. Wermer P. Genetic aspects of adenomatosis of endocrine glands. Am. J. Med, 1954; 16: 363.371.

30. Ying R, Feng J. Clinical significance of RET mutation screening in a pedigree of multiple endocrine neoplasia type 2A. Mol Med Rep 2016; 14: 1413-1417.

31. Zvara V, Pauer M, Balažovjech I, Kreze Májek, M Breza, J. Problém asymptomatických a maligných feochromocytómov. Lek Obzor 1996; 45: 209-211.

32. Zvara V, Pauer M, Balazovjech I, Kreze A, Majek M, Breza J. Problémes posés par les phéochromocytomes asymptomatique et les formes malignes de tumeurs de la medullo-surrénale. Ann Urol 1996; 30: 14-19. 